\title{
PRICING PRIVACY \\ THE RIGHT TO KNOW THE VALUE OF YOUR PERSONAL DATA
}

\author{
Gianclaudio Malgieri $^{1 *}$ \& Bart Custers $^{2}$
}

\begin{abstract}
The commodification of digital identities is an emerging reality in the data-driven economy. Personal data of individuals represent monetary value in the data-driven economy and are often considered a counter performance for "free" digital services or for discounts for online products and services. Furthermore, customer data and profiling algorithms are already considered a business asset and protected through trade secrets. At the same time, individuals do not seem to be fully aware of the monetary value of their personal data and tend to underestimate their economic power within the data-driven economy and to passively succumb to the propertization of their digital identity. An effort that can increase awareness and controllership of consumers/users on their own personal information could be making them aware of the monetary value of their personal data. In other words, if individuals are shown the "price" of their personal data, they can acquire higher awareness about their power in the digital market and thus be effectively empowered for the protection of their information privacy.

This paper analyzes whether consumers/users should have a right to know the value of their personal data. After analyzing how EU legislation is already developing in the direction of propertization and monetization of personal data, different models for quantifying the value of personal data are investigated. These models are discussed, not to determine the actual prices of personal data, but to show that the monetary value of personal data can be quantified, a conditiosine-qua-non for the right to know the value of your personal data. Next, active choice models, in which users are offered the option to pay for online services, either with their personal data or with money, are discussed. It is concluded, however, that these models are incompatible with EU data protection law. Finally, practical and moral problems of pricing privacy are discussed and it is concluded that, although some of these problems are significant, they should not outweigh the benefits of introducing a right to know the value of your personal data.
\end{abstract}

Keywords: privacy, personal data, data subject rights, big data, digital identities, data economy

\footnotetext{
${ }^{1}$ Gianclaudio Malgieri, LLM is a PhD Researcher at the Law, Science, Technology and Society studies (LSTS) of Vrije Universiteit Brussel, Belgium. Email Address: gianclaudio.malgieri@vub.ac.be, Address: Via Macerata 143, 56021 Cascina, PI, Italy. Tel: 00393888938827

${ }^{2}$ Bart Custers PhD MSc LLM is associate professor and head of research at eLaw, the Center for Law and Digital Technologies at the faculty of law of Leiden University, the Netherlands.
} 


\section{Introduction: from passive defence to active empowerment}

The commodification of digital identities is an emerging reality in the data-driven economy. ${ }^{3}$ Personal data of individuals represent monetary value in the data-driven economy and are often considered as a counter performance for "free" digital services or for discounts for online products and services. ${ }^{4}$ A recent proposal for an EU directive on the supply of digital content has acknowledged that personal data in the modern digital economy can be used, instead of money, to pay for digital content. ${ }^{5}$ At the same time, customer data and profiling algorithms are already considered a business asset and protected through trade secrets. ${ }^{6}$ However, problematic in this context is that individuals are not often aware of the monetary value of their personal data and tend to underestimate their economic power within the data market and to passively succumb to commodification of their digital identity. ${ }^{7}$

Awareness of individuals is a core element in the big data era and the data-driven economy: it is the optimal balancing between fostering innovation (through the free flow of data) and protecting individuals' human rights. Privacy and personal data protection has often been declined as a passive defence of individuals from collection, use and reuse of their data ${ }^{8}$. However, in the big data era, this seems to be both unrealistic and ineffective, because the limiting access and use of data is difficult to enforce and limits the opportunities that big data has to offer. ${ }^{9}$ Instead, a more realistic and effective approach towards effective protection of data subjects' interests would be an active empowerment of individuals in their personal data management.

An effort that can increase the awareness of and the control over their own personal information, could be making consumers/users aware of the monetary value of their personal data. ${ }^{10}$ In other words, if individuals are shown the "price" of their personal data, they can acquire higher awareness about their power in the digital market and thus be effectively empowered for the protection of their information privacy. ${ }^{11}$

This is possible by several means. From a theoretical perspective, several solutions have been proposed to make individuals active players in the data economy, e.g. by forms of "quasi-property"

\footnotetext{
${ }^{3}$ Corien Prins, The Propertization of Personal Data and Identities (2004), EJCL, www.ejcl.org/83/art83-1.html (accessed 12 June 2017). Nadhezda Purtova, The Illusion of Personal Data as No One's Property (2015), Law, Innovation and Technology, vol. 7, n. 1, 2015.

${ }^{4}$ See Wolfie Christl and Sarah Spiekermann, Networks of Control: A Report on Corporate Surveillance, Digital Tracking, Big Data \& Privacy (Facultas Verlags - und Buchhandels AG, 2016), 65-67.

${ }^{5}$ See Proposal for a Directive of the European Parliament and of the Council on certain aspects concerning contracts for the supply of digital content, $\operatorname{COM}(2015) 634$ final, Article 3 (1).

${ }^{6}$ Brenda Reddix-Smalls, 'Credit Scoring and Trade Secrecy: An Algorithmic Quagmire or How the Lack of Transparency in Complex Financial Models Scuttled the Finance Market', (2011) 12 U.C. Davis Bus. L.J. 87, $117-18$.

${ }^{7}$ Frederik Z. Borgesius., Behavioural Sciences And The Regulation Of Privacy On The Internet (2014), Amsterdam Law School Legal Studies Research Paper No. 2014-54.

8 World Economic Forum, Rethinking Personal Data: Strengthening Trust (2012), http://www3.weforum.org/docs/WEF_IT_RethinkingPersonalData_Report_2012.pdf (Accessed 9 June 2017 ), p. 9.

${ }^{9}$ Bart H.M. Custers, 'Click here to consent forever; Expiry dates for informed consent', (2016), Big Data \& Society, 16.

${ }^{10}$ See, e.g., Arslan Aziz and Rahul Telang, 'What Is a Digital Cookie Worth?' (March 31, 2016). Available at SSRN: https://ssrn.com/abstract=2757325 (accessed 12 June 2017).

${ }^{11}$ Richard G. Newell, Juha V. \& Siikamäki, 'Nudging Energy Efficiency Behaviour: The Role of Information Labels', (2014) 1 J. Association Environmental \& Resource Economists 555, 593; Cristiano Codagnone, Francesco Bogliacino and Giuseppe Veltri, Testing CO2/Car labelling options and consumer information, Final Report (2013), available at http://ec.europa.eu/clima/policies/transport/vehicles/labelling/studies_en.htm at 9.
} 
of individuals on their own data. ${ }^{12}$ From a more practical perspective, empowering individuals would mean enhancing controllership and awareness of data subjects in the data market. De lege lata, this is possible on the one hand through a full exercise of control rights (such as the right to data access, the right to rectification, the right to data portability, the right to be forgotten and the right to block the processing) and on the other hand through the right to receive appropriate information about data processing. An effort that can conciliate the theoretical approach to quasipropertization of personal data and the practical approach to increase awareness and controllership of consumers/users on their own personal information could be making data subjects aware of the monetary value of their personal data. ${ }^{13}$

The traditional, passive approach to informational privacy has only protected data as per their personal/emotional (qualitative) value, but in order to reduce information asymmetry in the big data era and to make individuals stronger players in this data-driven economy, what is necessary is to provide more and more information about the monetary (quantitative) value, i.e., the quantum of their personal data value. This may better indicate the power that individuals really have or can have. It has been shown that if individuals were shown the price of their personal data, their awareness about data processing implications would strongly increase. ${ }^{14}$ In this paper we propose de lege ferenda - to introduce a new right of data subjects to receive from data controllers (or an obligation for data controllers to provide to data subjects) information about the monetary value of their personal data.

Firstly, it is analyzed how different types of business models trade personal data in the data-driven economy. These business models can be categorized according to their incentive structures (i.e., monetary and non-monetary) and types of use cases (i.e., providing online content, online services or offline services). Also, it is analyzed how EU legislation is already developing in the direction of propertization and monetization of personal data.

Secondly, objective parameters for (estimate) pricing of data are examined, since providing data subjects with a right to know the value of their personal data is only feasible if it is actually possible to quantify the value of these personal data. Different pricing models are discussed, not to determine the actual prices of personal data, but to show that the monetary value of personal data can be quantified, a conditio-sine-qua-non for the right to know the value of your personal data. Objective parameters for pricing personal data are established via two methods: a top-down and a bottom-up approach. The first approach corresponds to the supply of digital data, while the second one corresponds to the demand of digital data. The top-down approach corresponds to the demand for digital data and an objective parameter can be found in the price that companies generally pay for personal data of individuals. There are already several studies on this subject, which are based on the businesses' turnover derived from personalized advertisements. ${ }^{15}$ The bottom-up approach

\footnotetext{
${ }^{12}$ Gianclaudio Malgieri, 'Ownership" of Customer (Big) Data in the European Union: Quasi-Property as Comparative Solution?', (2016) Journal of Internet Law, Vol. 20, n.5, 2 ff.

${ }^{13}$ See, e.g., Arslan Aziz and Rahul Telang, 'What Is a Digital Cookie Worth?' (2016). Available at SSRN: https://ssrn.com/abstract=2757325 (accessed 12 June 2017).

${ }^{14}$ Richard G. Newell, Juha V. \& Siikamäki, 'Nudging Energy Efficiency Behaviour: The Role of Information Labels', (2014) 1 J. Association Environmental \& Resource Economists 555, 593, Cristiano Codagnone, Francesco Bogliacino and Giuseppe Veltri, Testing CO2/Car labelling options and consumer information, Final Report (2013), available at http://ec.europa.eu/clima/policies/transport/vehicles/labelling/studies_en.htm (accessed 12 June 2017), at 9.

${ }^{15}$ John Rose, Olaf Rehse, and Björn Röber, The value of our digital identity (2016, New York: The Boston Consulting Group). See also Arslan Aziz and Rahul Telang, 'What Is a Digital Cookie Worth?', op.cit.
} 
corresponds to the supply of digital data and is based on a "reverse liability" paradigm, ${ }^{16}$ i.e., measuring the value of personal data in terms of damage to privacy or loss of privacy ${ }^{17}$ and also in terms of increase of consumer asymmetry.

Thirdly, it is necessary to find a practical way in which this explicit pricing of personal data can be introduced in the digital market. It has already been proposed as a solution to provide an active choice to data subjects: ${ }^{18}$ when individuals register for a service, they might be asked if they want to pay with money or with their personal data (and with this they usually accept that data controllers use algorithms to profile their personality). It will be shown, however, that these active choice models are not compatible with the new EU data protection legislation (the General Data Protection Regulation). Article 7(4) states that when assessing whether consent is freely given, utmost account shall be taken of whether, inter alia, the performance of a contract, including the provision of a service, is conditional on consent to the processing of personal data that is not necessary for the performance of that contract. In other words, it is not possible for service providers to deny the provision of a digital service after the consent to personal data processing that is not necessary for performing the contract has been withdrawn. Indeed, if customers accept to "pay by data" and later withdraw their consent regarding the processing of unnecessary personal data, they cannot be denied the provision of the digital service. As a result, service providers and data controllers may end up without payment for their services.

That is why a new data subject right or data controllers "information duty" is the only legal option compatible with the EU privacy approach. What we propose here is an alternative solution: the addition of a new specific obligation to the "information duties" (e.g., under article 13 of the EU General Data Protection Regulation): in all forms of data processing in which the value of data subject's personal data is relevant for the economic transaction, the price of these data (calculated on objective parameters) should be communicated to the data subject. Such a disruptive proposal may increase the shift from privacy as a passive protection, to privacy as an active empowerment of individuals and may, as such, enhance the protection of the right to data protection that each individual has under Article 8 of the EU Charter of Fundamental Rights.

It is obvious that this proposed right to know the value of your personal data also entails several practical problems (such as choosing a pricing method, issues regarding control and consent and issues regarding governance and enforcement) and moral problems (such as the commodification of inalienable and non-negotiable human rights and the potential reinforcement of existing disparities in society). For instance, data subjects having a lower propensity to consume and presumably lower incomes have less valuable data than other consumers ${ }^{19}$ and could have worse contractual

\footnotetext{
${ }^{16}$ Guido Calabresi and A. Douglas Melamed, 'Property Rules, Liability Rules, and Inalienability: One View of the Cathedral' (1972), Faculty Scholarship Series, Paper 1983, 1116 as rephrased (in the field of personal data) by Gintare Surblyte, 'Data as Digital Resource', (2016). Max Planck Institute for Innovation \& Competition Research Paper No. $16-12,37$.

${ }^{17}$ Daniel J. Solove, and Danielle K. Citron, 'Risk and Anxiety: A Theory of Data Breach Harms' (forthcoming 2017) 96 Texas Law Review.

${ }^{18}$ Bilyana Petkova and Philipp Hacker, 'Reining in the Big Promise of Big Data: Transparency, Inequality, and New Regulatory Frontiers' (2016), Lecturer and Other Affiliate Scholarship Series. Paper 13.

${ }^{19}$ Emily Steel, Callum Locke, Emily Cadman and Ben Freese, 'How much is your personal data worth?', Financial Times, (12 June 2013), available at http://www.ft.com/cms/s/2/927ca86e-d29b-11e2-88ed00144feab7de.html?ft_site=falcon\#axzz2z2agBB6R (accessed 12 June 2017). see also Emily Steele, Financial worth of data comes in at under a penny a piece, Financial Times, June 12, 2013.
} 
conditions. ${ }^{20}$ We recognize that some of these problems are significant and provide some suggestions to mitigate them. Even though not all of these problems can be solved, we think these do not outweigh the benefits of introducing a right to know the value of your personal data.

This paper is structured as follows. Section 2 investigates different types of business models that trade personal data in the data-driven economy and analyzes how EU legislation is already developing in the direction of propertization and monetization of personal data. Section 3 investigates how the value of personal data can be quantified. It is not tried to determine the actual prices of personal data, but to show that the monetary value of personal data can be quantified. Section 4 examines why active choice models are not a viable alternative to empower people, as this is incompatible with EU data protection law. Section 5 examines practical and moral problems that the right to know the value of your personal data may raise. Suggestions are made on how to mitigate these problems. Section 6 provides conclusions.

\section{De facto monetisation of personal data already at stake}

The monetization of personal data is already a reality in nearly all fields of the digital market. The European Commission has highlighted that the market for consumers' data is growing fast and business models based on monetizing data become predominant ${ }^{21}$ and a large share of consumers access digital services offered in return for their personal data. This is the case for around $30 \%$ of antivirus and navigation software and cloud storage services, $77 \%$ of streamed events and more than $50 \%$ of movies, film, TV content, e-books and games ${ }^{22}$. Ensuring an adequate level of protection for these consumers would increase overall consumers' confidence. ${ }^{23}$ The economic advantage for customers is balanced by the value of personal profiling which they usually allow by disclosing their personal data. In more technical terms, we can enlist at least three use cases:

a. the "free" or discounted provision of online services,

b. the "free" or discounted provision of (valuable) online content

c. and a "free" or discounted provision of an "offline" service (e.g., insurance, mortgage).

Regarding the first type of use cases, "free" online services", some relevant examples are "free" wifi services in public spaces, for instance, in airports, when users need to accept cookies and trackers and give their email address if they want to navigate on the Internet. In other words, if they want a free provision of Internet data, they must disclose to the provider (and often to provider's partners) a chronology of websites visited, queries, mailing address, location data, etc. and thus accept a personal profiling. ${ }^{24}$ Similar considerations can be made for free cloud services or social networks. A typical example of the second type of use cases are music platforms, like Spotify, where users can access nearly all kind of songs or music pieces at high quality, even if protected by copyright, for free. Customers are asked to create a social profile and to authorize Spotify access to

\footnotetext{
${ }^{20}$ Lauren Henry Scholz, 'Algorithmic Contracts' (2016), Stanford Technology Law Review, Forthcoming. Available at SSRN: https://ssrn.com/abstract=2747701 (accessed 12 June 2017)

${ }^{21}$ Commission Staff Working Document, Impact Assessment Accompanying the document Proposals for Directives of the European Parliament and of the Council (1) on certain aspects concerning contracts for the supply of digital content, $\mathrm{COM} / 2015 / 0634$ final

22 Ibid.

${ }^{23}$ Ibid.

${ }^{24}$ See, e.g., Ningning Chen, Xinlei Oscar Wang, Prasant Mohapatra, Aruna Seneviratne, 'Characterizing privacy leakage of public WiFi networks for users on travel Conference Paper' in Proceedings IEEE INFOCOM (2013).
} 
their profile data on Facebook. An example of the third type of use cases is the discount in life insurance policies when using of health trackers. In 2015, John Hancock, one of the largest life insurers in the U.S., teamed up with Vitality, a corporate wellness provider, to offer policy holders a discount when they let a free Fitbit device track their activities. Consumers receive personalized health goals and can log their activities using online and automated tools. By gaining so-called "Vitality Points" they can get a discount of up to $15 \%$ on their life insurance policy. ${ }^{25}$

The classification of "free" or discounted provision of digital services, digital content or offline services can also be observed under a different perspective. ${ }^{26}$ In strictly economical terms, the transaction between a consumer and a company where there is a mutual exchange of products or services and information is called a "composite transaction" and is different from an "information transaction" when there is a mere flow of information from the consumer to the company. Composite transactions are based on two different steps: the company offers services or products and the consumer purchases them. When the company offers services or products, it also provides information regarding these goods or services and regarding the transaction. At the same time, when the consumer purchases the service or product he or she can "pay" in different manners. Usually in the digital market it is possible to pay with money, with (personal) information, or both. This is sometimes referred to as "disclosure as by-product" ${ }^{27}$

Since the disclosure of data is an additional element of the traditional exchange of products or services for money, in terms of business models, these business-to-consumer transactions can be classified as follows:

1. Monetary incentives for disclosure as by-product:

1.1. Savings: consumers are encouraged to disclose their personal data by a discount covering a part or the totality of the price.

1.2. Earnings: consumers are encouraged to disclose their personal data via a monetary benefit (e.g. a digital wallet). ${ }^{28}$ There are in particular two companies who provide "digital wallets" for the disclosure of personal data: Handshake and Brave. The former is a platform for finding a job where disclosing personal data can turn into money. ${ }^{29}$ The latter is a browser which blocks all online ads, except those from known advertisers that have accepted to share a part of their income with data users; accordingly users can earn digital money that they can only spend on financing their favourite content provider. ${ }^{30}$

2. Non-monetary incentives for disclosure as by-product:

\footnotetext{
${ }^{25}$ Wolfie Christl, Sarah Spiekermann, Networks of Control: A Report on Corporate Surveillance, Digital Tracking, Big Data \& Privacy (Facultas Verlags- und Buchhandels AG, 2016), 66-67 and 290. See also John Hancock (2015): 'John Hancock Introduces a Whole New Approach to Life Insurance in the U.S. that Rewards Customers for Healthy Living' (April 8, 2015), http://www.johnhancock.com/about/news_details.php?fn=apr0815-text\&yr=2015, (accessed 12 June 2017). See also for more detalis on the Fitbit program: http:/www.thevitalitygroup.com/john-hancock-entersexclusive-partnership-with-vitality (accessed 12 June 2017).

${ }^{26}$ see Nicola Jentzsch, State-of-the-Art of the Economics of Cyber-Security and Privacy, IPACSO - Innovation Framework for ICT Security Deliverable, No. 4.1 (2016), § 3.2.1.

${ }^{27}$ Nicola Jentzsch, Andreas Harasser, Sören Preibusch, Monetising Privacy - An Economic Model of the Pricing of Personal Information, ENISA Report, (2012) Greece, www.enisa.europa.eu/activities/identity (accessed 12 June 2017).

${ }^{28}$ This classification is only partially taken from Nicola Jentzsch, The-state-of-the-Art, (2016), op.cit. § 3.2.1, Table 8. Actually that classification does not consider the case of no incentives and classifies differently the monetary incentives, i.e. "earnings" and "payments", where earnings means any economic advantage, while payments means that consumers pays in order to control more their information.

${ }^{29}$ Natasha Lomas, 'Handshake Is A Personal Data Marketplace Where Users Get Paid To Sell Their Own Data', Tech Crunch, (2 September 2013), <https://techcrunch.com/2013/09/02/handshake/> (accessed 28 May 2017).

${ }^{30} \mathrm{See}<$ https://brave.com/assets/img/press/brave_infographic_large.png $>$ (accessed 29 may 2017).
} 
2.1. A counter-service, in particular personalization: consumers are encouraged to disclose their personal data by a more tailored service, e.g., a personalized search engine or a personalized social network platform. In some cases, the online services offered may lose some functionality when they cannot be personalized.

2.2. No incentives: none of the above incentives applies. In these cases, often consumers have an all-or-nothing choice when disclosing their personal data.

Combining this transaction structure classification with the different types of use cases mentioned above yields different business models. Table 1 shows examples of companies using these different types of business models.

\begin{tabular}{|c|l|l|l|l|}
\hline \multirow{2}{*}{ Incentives } & \multicolumn{2}{|c|}{ Monetary } & \multicolumn{2}{c|}{ Non-monetary } \\
\cline { 2 - 5 } & Savings & Earnings & Personalization & No incentives \\
\hline Digital Content & Spotify & & Spotify & iTunes \\
\hline Digital Service & $\begin{array}{l}\text { wifi in public } \\
\text { spaces, Antivirus }\end{array}$ & Brave & $\begin{array}{l}\text { Google, } \\
\text { Facebook }\end{array}$ & Groupon \\
\hline Offline Service & $\begin{array}{l}\text { Hancock } \\
\text { insurance }\end{array}$ & Handshake & Experian & $\begin{array}{l}\text { Traditional } \\
\text { insurance, etc. }\end{array}$ \\
\hline
\end{tabular}

Table 1: Examples of companies using different business models based on different transaction structures and different use cases.

\subsection{Monetization of data in EU legislation}

EU legislation is increasingly taking into account the reality described above. A typical example is the proposed EU directive on "certain aspects concerning contracts for the supply of digital content". ${ }^{31}$ With regard to the provision of valuable online content for free, the scope of this proposed directive is restricted in Article 3(1) to any contract where the supplier provides digital content to the consumer or undertakes to do so and, in exchange, a price is to be paid or the consumer actively provides counter-performance other than money in the form of personal data or any other data". Recital 13 remarks indeed that "in the digital economy, information about individuals is often and increasingly seen by market participants as having a value comparable to money. Digital content is often supplied not in exchange for a price but against counterperformance other than money, i.e., by giving access to personal data or other data. Those specific business models apply in different forms in a considerable part of the market".

The choice to consider also "free" services "paid by data" within the scope of the proposed directive is due to many factors. First of all, introducing a differentiation depending on the nature of the counter-performance would discriminate between different business models providing an unjustified incentive for businesses to move towards offering digital content against data. In addition, "defects of the performance features of the digital content supplied against counterperformance other than money may have an impact on the economic interests of consumers". In

\footnotetext{
${ }^{31} \mathrm{COM} / 2015 / 0634$ final.
} 
other words, a narrow scope would not ensure a high level and future-proof consumer protection. ${ }^{32}$ In addition, the impact assessment underlines that the strongest impact of rules covering digital content provided in exchange for personal data will be increasing consumers' awareness of the economic value of their personal data and further contribute to better protection.

Recital 14 clarifies also that that Directive shall apply only when the customer actively supplies the data (so excluding the case in which the customer accepts cookies), which are not necessary for the digital content to function in conformity with the contract. According to the principle of data minimization (see Article 5(1)(c), GDPR) personal data processed must be adequate, relevant and limited to what is necessary in relation to the purposes for which they are processed. In other words, unless paying with sources "other than money" is part of the declared (and legitimate) purpose, any form of processing of data that are unnecessary for the execution of a contract might be a violation of data minimization principle. The impact assessment of the proposed directive clarifies that the extended scope is consistent with the existing personal data protection framework, which recognises the high importance and value of personal data and that "it does not overlap with data protection rules". However, in order to respect and not overlap with data protection rules, the only possibility is that the data controller when collecting data declares the purpose of such data processing and the value the data represents.

Obviously, this is still a proposal and the European Commission mentions also (in its impact assessment) that companies (including those active in the field of digital content development) are against such an extension and advised against overlaps with data protection rules. In particular, some companies argued that the focus should not be on whether the data had been actively provided but rather on how this data is used by the data controllers. For our purposes, we must at least highlight that the EU legislator is starting to acknowledge the de facto monetisation of personal data and is trying to regulate it, though indirectly.

Also some digital service providers are starting to admit (perhaps unconsciously) that personal data and user-generated content are a form of payment. A typical example is the End-User Licence Agreement of Instagram, in which Article 1 states that "on Instagram the user provides Instagram with a non-exclusive licence, totally paid [for with] the use of content that he or she publishes on Instagram". ${ }^{33}$ On Instagram the registration is free and users do not receive any monetary benefit when they share content (such as images), so the expression "totally paid" seems to refer to non-monetary payment. In other words, according to Instagram's Terms of Use, ${ }^{34}$ it seems that users and service providers perform a transaction in which users pay to Instagram for registration, while Instagram pays to users for having a licence on user generated content. These bilateral payments balance out into a zero-sum and so a "free" digital transaction reveals to be a (implicitly) non-free transaction.

\section{Quantifying the value of personal data}

\footnotetext{
${ }^{32}$ See the Impact Assessment, supra.

${ }^{33}$ See Instagram Terms of Use, $\S$ "Rights", Art. 1, < https://help.instagram.com/478745558852511> accessed 29 May 2017. Italics added.

${ }^{34}$ The deceptive nature of Social media Terms of Use has been however addressed recently in European Commission Press release, The European Commission and Member States consumer authorities ask social media companies to comply with EU consumer rules, Brussels, 17 March 2017, < http://europa.eu/rapid/press-release IP-17-631_en.htm> (accessed 29 May 2017).
} 
When asking how much a person's data is worth, the answer is: not much. General information about a person, such as age, gender and location is worth a mere 0.05 cent. Persons who are shopping for a car, a financial product or a vacation are more valuable to companies that want to pitch those goods. For instance, personal data of auto buyers are worth about 0.21 cent per person. ${ }^{35}$ Personal data of people going through certain life events, such as becoming a parent, moving, getting engaged or getting divorced, also prompt companies to pay more for personal data. For instance, personal data of a pregnant woman are worth about 11 cent. ${ }^{36}$ More sensitive personal data are more valuable. Personal data containing specific health conditions or information on taking certain prescriptions are worth about 26 cent per person. But even adding up all these details means the sum total for most individuals is less than a dollar. ${ }^{37}$ However, in principle the data can be sold and resold many times.

It is important to mention that with the development of the data economy, prices of personal data are rapidly going down. For instance, a zip code in the US cost 50 cents in 2006 and 0,05 cents in $2013 .^{38}$ This is not only due to lower costs of data collection, but also due to a significant increase in the use of personal data for profiling and marketing. ${ }^{39}$ Furthermore, personal data has become ubiquitous, particularly in the United States where personal data can be traded freely, which also drives down prices.

Providing data subjects with a right to know the value of their personal data is only feasible if it is actually possible to quantify the value of these personal data. It is sometimes argued that the value of personal data is intangible, risk-dependent, context-dependent and diffuse ${ }^{40}$. Also, the underlying values that are at stake, such as privacy, are hard to quantify. For instance, disclosure of personal data may lead to increased risks of future identity theft or fraud, but interpreting such increased risks as actual harm may be too speculative. ${ }^{41}$ It might be argued that if it is impossible to quantify the value of personal data, then granting data subjects a right to know the value of their personal data is not realistic.

However, in this section we argue that assessing the value of personal data is not impossible. It is not even that difficult. But there are some choices to be made, as there exist multiple ways to assess the value of personal data. Attaching a monetary value to personal data requires some clarity on (1) how to express monetary value, (2) which object is actually being priced, and (3) how to attach the value to the object, i.e., the actual pricing system. Hence, in Section 3.1 we start with discussing in which units the value of personal data could or should be expressed. In Section 3.2 we discuss which object is actually being priced and related pricing factors. In Section 3.3 we discuss a number of ways in which the value of personal data can be assessed. These are concrete pricing systems for personal data.

\footnotetext{
${ }^{35}$ Emily Steel, 'Financial worth of data comes in at under a penny a piece', (2013), op.cit.

${ }^{36}$ Ibid.

${ }^{37}$ The Financial Times has developed a calculator for what a person's personal data is worth. By answering questions on demographics, family $\&$ health, property, activities and consumer characteristics, a person can calculate the value of his or her personal data. See http://www.ft.com/cms/s/2/927ca86e-d29b-11e2-88ed00144feab7de.html?ft site=falcon\#axzz4dMtRPoZd (accessed 12 June 2017).

38 Jay MacDonald, 'How much are your personal details worth?', (21 February 2006), Bankrate.com, http://www.bankrate.com/nsccan/news/pf/20060221b1.asp (accessed 12 June 2017).

${ }^{39}$ More-with-mobile, 'Prices and Value of Consumer Data' (2013) http://www.more-with-mobile.com/2013/06/pricesand-value-of-consumer-data.html (accessed 12 June 2017).

${ }^{40}$ OECD, Data-driven Innovation for Growth and Well-being, Interim Synthesis Report (2014).

${ }^{41}$ See, for instance, US case law: Forbes v. Wells Fargo Bank, 420 F. Supp. 2d 1018 (D. Minn. 2008); Guin v Higher Educ. Serv. Corp. Inc. 2006 WL 288483 (D. Minn. 2006).
} 


\subsection{Expressing value}

Before discussing these pricing systems, it is important to first consider the way in which to express the value of personal data. Intuitively, it would make sense to express the monetary value of personal data in a currency like dollars or euros. However, since personal data are a different product than other, tangible products there are some issues that require further qualifications of this currency based pricing approach.

The first issue is that personal data change over time and may get outdated. For instance, people move and get other addresses. Also, people may change their interests over time, sometimes gradually (for instance, when they grow older), sometimes immediately (for instance, when they have big life events, like getting married, getting children, facing serious diseases, etc.). As a result, personal data may change and get outdated and, most importantly in this discussion, may lose some of its value. Although we are not suggesting that historical data may not have any value, for purposes like advertising personal data that is up-to-date has the most value. After data (or aggregated datasets) grow older, their value may decrease. Data has to be 'fresh' to be attractive for companies. Hence, it makes sense to argue that personal data is a dynamic product, rather than a static product. Accordingly, it could be argued that the value of personal data may be expressed in terms of euros or dollars per month, rather than in euros or dollars. As will be explained below, this also reflects pricing systems that use subscriptions and leases of data rather than selling data.

The second issue is that data, also personal data, can easily be reused. ${ }^{42}$ Contrary to tangible products that can only be sold once by a particular owner, data can be copied without additional costs and sold multiple times. Hence, when someone owns personal data, he or she can sell it multiple times. A data subject can sell his or her personal data to different companies. The number of times data can be reused, determines its value. From the perspective of the data subject, it may be interesting to reuse the same personal data many times to create more value. However, from the perspective of a company that collects personal data, it can only collect personal data from each data subject once. Obviously data collectors can strive for collecting more detailed and complete data on each data subject, each piece of data can only be collected once (unless it has become outdated as explained above). Hence, from the perspective of data collectors it makes sense to express the value of personal data in terms of euros or dollars per person, rather than in euros or dollars.

\subsection{Pricing factors}

In the previous section, the term personal data was used in a general way. When raising the question what the value of someone's personal data is, the immediate response is: which data? Does this refer to all of your personal data or to a specific set, like the personal data on someone's Facebook profile, someone's credit card details or someone's online behaviour and preferences? In this section, we discuss which object is actually being priced when pricing privacy or pricing personal data and related pricing factors.

\footnotetext{
${ }^{42}$ Bart H.M. Custers \& Helena Ursic, 'Big data and data reuse: a taxonomy of data reuse for balancing big data benefits and personal data protection' (2016), International Data Privacy Law 6(1): 4-15.
} 
A first step in this brief analysis is to consider pricing each individual attribute in a personal record. It could be argued that personal data consists of many different attributes of a data subject, often starting with his or her name, address and city of residence. Other common attributes are date of birth, gender, marital status, profession, bank account numbers, etc. More subjective attributes include, for instance, hobbies, interests, preferences. Some of these attributes may also be objective, when predicted on the basis of big data. ${ }^{43}$ Such predictions and statistics may include preferences, life expectancies, credit scores and health risks. We argue that it does not make sense to price the value of each individual attribute in a personal record, as it is the combination of attributes that actually creates value. When the attribute name is provided as 'John' or the attribute gender is provided as 'male', these are meaningless. Single attributes without any further context have no monetary value. Only when combined, i.e., when John is male, these attributes create value.

Hence, pricing personal data is not about pricing individual attributes, but either about pricing attributes of a person or about pricing combinations of attributes. In other words, pricing personal data is about datasets, not about single data, where a datasets starts with combining two data items. In practice, however, many datasets are much larger, increasing the value of personal data. For instance, Axciom, one of the leading US personal data brokers has an average of 1,500 pieces of information on each data subject. ${ }^{44}$ It can also be argued that pricing personal data is in fact pricing digital identities, which are the sum of all digitally available information about an individual. ${ }^{45}$ These digital identities are becoming increasingly complete and traceable, driven by the exponential growth of available data and technologies to combine and process these data. Pricing digital identities or digital profiles (rather than single attributes) also corresponds better to the practice in which companies that purchase datasets are usually obliged to buy in bulk. ${ }^{46}$

In fact, the size of datasets and the completeness of datasets are important factors in determining the monetary value of personal data. Knowing that John is male is probably worth less than knowing that John is a male, 35-year old married physician living in a Milwaukee suburb and interested in baseball, jogging and movies. Still, the missing surname of John may affect the value of these personal data negatively. Also, the accuracy and extent to which these data are up-to-date affect the monetary value of these personal data. For instance, when these data refer to 1952, they represent a different value then when they refer to 2017. It is important to note that accuracy rates in datasets are often low. For instance, Acxiom, one of the leading US personal data brokers, has estimated accuracy rates of $50 \%{ }^{47}$

Some data items in a record or profile may be worth more than other data items. For instance, several sensitive characteristics, such as those referring to ethnicity, religion, health, union membership, politics, criminal records, substance abuse and sexual preferences, are more 'telling' about people. Many people also tend to treat these characteristics with more care and disclose them less often. As such, the availability and nature of these characteristics is more rare and unique and

\footnotetext{
${ }^{43}$ Bart H.M. Custers, 'Predicting Data that People Refuse to Disclose; How Data Mining Predictions Challenge Informational Self-Determination', (2012) Privacy Observatory Magazine 2012(3).

44 Paul Boutin, 'The Secretive World of Selling Data about You' (2016), Newsweek, http://www.newsweek.com/secretive-world-selling-data-about-you-464789 (accessed 12 June 2017).

${ }^{45}$ John Rose, Olaf Rehse, and Björn Röber, The value of our digital identity (2016, New York: The Boston Consulting Group).

${ }^{46}$ More-with-mobile, 'Prices and Value of Consumer Data' (2013) http://www.more-with-mobile.com/2013/06/pricesand-value-of-consumer-data.html (accessed 12 June 2017).

47 Paul Boutin, 'The Secretive World of Selling Data about You' (2016), Newsweek, http://www.newsweek.com/secretive-world-selling-data-about-you-464789 (accessed 12 June 2017).
} 
makes them harder to collect. As in general economics, when there is less supply, prices tend to go up. $^{48}$

A final pricing factor is the level of identifiability of personal data. ${ }^{49}$ Anonymous data does have monetary value, as it may be very useful for several purposes, including policy-making, strategic decision-making and scientific goals. Big data may reveal patterns that are useful for targeted approaches that are not on an individual level. For instance, knowing that diapers and beer cans are usually bought together by customers, especially on Saturdays, is anonymous data that is very useful for targeted marketing and advertising. Nevertheless, knowing the identifying data of the individuals that fall into this category may be worth even more, as it allows an even further personalised marketing and advertising approach.

In summary, when pricing personal data it makes sense to focus on datasets (i.e., digital identities or digital profiles) rather than on pricing individual attributes. Altogether there are many factors that affect the price of personal data. Factors as size, completeness, accuracy, being up-todate, rareness and uniqueness, and identifiability can all influence the value. The question is obviously how to add weight to these factors. That, in short, depends on the context and purposes for which the personal data are collected and used. How to determine the actual value of personal data is discussed in the next section.

\subsection{Pricing systems}

There is research available on estimating the value of personal data. A good starting point is OECD survey on methodologies for measuring monetary value of personal data. ${ }^{50}$ OECD distinguishes methods that are based on market valuation, and methods that are based on individual's valuation. The market valuation methods focus on (a) financial results for data records, i.e., market cap/revenues/net income per data record, (b) market prices for data, i.e., price per personal data entry offered on the market by data brokers, (c) cost of a data breaches, i.e., economic cost of a data breach (for firms and individuals) per data entry and (d) data prices in illegal markets, i.e., estimation of prices of personal data in illegal markets. The individual's valuation methods focus on (e) surveys and economic experiments, i.e., valuation of personal data in monetary terms that are reported by individuals in surveys or economic experiments and (f) data on willingness of users to pay to protect their data, i.e., amounts that individuals are ready to spend to protect their personal data.

Each of these elements has its drawbacks. As for market-based valuations, the problem is that other factors are often priced-in and several externalities are not considered. ${ }^{51}$ For financial results (a), it is highly dependent of the revenues and income of a specific companies. For market prices (b), it does not consider the different contexts in which data are demanded. For cost of data breaches (c), there is not any direct proportionality between damages caused by data breach and the actual value of personal data (e.g., damages may include also other factors, like damages to cyberinfrastructures). For illegal markets (d) it does not consider the costs of illegal activities in terms of

\footnotetext{
${ }^{48}$ At the same time, the value of redundant data is zero. For instance, when a record shows both someone's age and date of birth, one of these can be used to calculate the other.

${ }^{49}$ See Nicola Jentzsch, State-of-the-Art of the Economics of Cyber-Security and Privacy, op.cit., \$ 3.2.3.2.

${ }^{50}$ OECD, Exploring the Economics of Personal Data: A Survey of Methodologies for Measuring Monetary Value, OECD Digital Economy Papers, No. 220, (2013, OECD Publishing).

${ }^{51}$ Nicola Jentzsch, State-of-the-Art of the Economics of Cyber-Security and Privacy, op.cit., § 3.8.1
} 
risks for intruders. ${ }^{52}$ All these measures are unilateral and incomplete. Furthermore, they do not consider how much the data are worth for data subjects. However, individual-based valuations (e and $\mathrm{f}$ ) are also incomplete, because they are not incentive-compatible. ${ }^{53}$ Especially for willingness to pay to protect data (f) it has been proven that it does not capture the actual perceived value of personal data. ${ }^{54}$

A hybrid methodology which compares a bottom-up and a top-down approach has been proposed by Petkova and Hacker (2016). ${ }^{55}$ The bottom-up approach starts with assessing the value of personal data for advertising. Companies can charge roughly ten times more for personalized advertising than for standard advertising. This difference can be explained by the fact that personalised advertising is a more targeted approach in which no efforts, time and money are wasted on people who are unlikely to respond the advertising anyway. According to industry sources, 1000 personalised advertisements on Facebook mobile would cost approximately 50 cents and about one dollar for the desktop version of Facebook. Hence, each personalized advertisement costs between 0.05 and 0.10 cents.

As discussed in Section 3.1, it may be argued that a price per month makes more sense than a single price expressed in euros or dollars. Assuming that the average users sees about 20 advertisements a day, the revenue from personalized advertising based on personal data for a single data subject is between 1 and 2 cents per day or between 30 and 60 cents per month. ${ }^{56}$ Obviously, this does not include any further sale, lease or subscriptions to the same data. When this is included, it is likely that the value of personal data will be in the range of 1 to 10 dollars.

The top-down approach estimates the value of personal data with a different calculation strategy, in which the total revenue and the total number of users of a company processing personal data are used as a starting point. For instance, Facebook had a total revenue of 17.93 billion dollars in 2015, most of which was revenue from advertising. ${ }^{57}$ At the end of 2015 , the total number of users was 1.59 billion. ${ }^{58}$ Thus, Facebook generates an average of about ten dollars of revenue from advertising per per year, which is about one dollar per month. The results of this calculation are in line (same magnitude) with the bottom-up approach.

This approach does not take into account the price at which data subjects would be likely to disclose their own personal data. That is why it may be argued that the loss of privacy is also included in the pricing of personal data. Since individuals tend to under-estimate the effects of disclosing their own personal data and are often unconscious of inferences, predictions and discrimination that can arise from personal data that they disclose, ${ }^{59}$ the impact of privacy harms can better be determined by Data Protection Authorities. Privacy harms can be either subjective

\footnotetext{
${ }^{52}$ Ibid. See also OECD, Exploring the Economics of Personal Data, op.cit.

${ }^{53}$ Nicola Jentzsch, State-of-the-Art of the Economics of Cyber-Security and Privacy, 2016, op.cit., § 3.8.1.

${ }^{54}$ Alessandro Acquisti, Leslie John and George Loewenstein, 'What Is Privacy Worth?', (2013) Journal of Legal Studies: 42 (2)1, http://chicagounbound.uchicago.edu/jls/vol42/iss2/ (accessed 28 May 2017).

${ }^{55}$ Bilyana Petkova and Philipp Hacker, 'Reining in the Big Promise of Big Data: Transparency, Inequality, and New Regulatory Frontiers', (2016) Yale Law School: Lecturer and Other Affiliate Scholarship Series, paper 13.

${ }^{56}$ This is in line with other sources, for instance, More-with-mobile, 'Prices and Value of Consumer Data' (2013)

http://www.more-with-mobile.com/2013/06/prices-and-value-of-consumer-data.html (accessed 12 June 2017).

${ }^{57}$ See www.marketwatch.com/investing/stock/fb/financials (accessed 12 June 2017).

${ }_{58}$ See www.statista.com/statistics/264810/number-of-monthly-active-facebook-users-worldwide (accessed 12 June 2017).

${ }^{59}$ Bart H.M. Custers, Simone van der Hof S\& Bart Schermer, 'Privacy Expectations of Social Media Users: The Role of Informed Consent in Privacy Policies’, (2014) Policy and Internet 6(3): 268-295.
} 
harms (i.e., the distress for data breach) ${ }^{60}$ or objective harms (i.e., information asymmetry and discrimination). ${ }^{61}$ When individuals disclose their data they suffer an objective loss of privacy in terms of higher exposure to discrimination (including price discrimination) and information asymmetry, which may yield commercial vulnerability. Subjective harms may be difficult to quantify, though this may not be entirely impossible. ${ }^{62}$ Objective harms are more straightforward to be quantified by courts or Data Protection Authorities. There is case law available that has monetized privacy damages in terms of discrimination and vulnerability risks. ${ }^{63}$ Obviously, these examples of pricing privacy by courts involve cases in which actual violations of privacy rights took place. These pricing methods can be used in the context of the right to know the value of your personal data by applying so-called "reverse liability". ${ }^{64}$ This means calculating a compensation that a potential infringer (e.g., a company, a data controller) pays ex ante in order to be allowed to perform a probably harmful activity (e.g., processing personal data).

The wide range of methods discussed in this section shows that monetary value of personal data value can be quantified. The aim of this paper is not to determine the actual prices of personal data, but to show that this important requirement for the right to know the value of your personal data is not an obstacle.

\section{4. "Active choice" models and the GDPR}

There are several ways to increasing consumers' awareness about monetisation of personal data in the modern information society. It may be suggested that there are better alternatives for a right to know the value of your personal data. Particularly so-called "active choice" models are often mentioned in this respect. ${ }^{65}$ These models refer to an active choice for consumers between paying for a digital service with money (without any consent to the service provider to perform a profiling on the customer data) and accessing the service for free while disclosing personal data, usually allowing personal profiling. In other words, the active choice is between paying by data and paying by money. At the same time, data controllers who provide digital services would have the obligation to provide this active choice to their customers. This approach addresses the problem of unilateral monetisation of personal data in the modern digital economy and it proposes an effective safeguard that might actively increase awareness of data subjects and empower them in the digital market. Indeed, according to the "active choice" model, the flow of data or money in the supply of digital services would depend on individual choices.

\footnotetext{
${ }^{60}$ See Daniel J. Solove \& Danielle Keats Citron, 'Risk and Anxiety: A Theory of Data Breach Harms', (2017) GW Law School Public Law and Legal Theory Paper No. 2017-2.

${ }^{61}$ Ryan M. Calo, 'The Boundaries of Privacy Harm' (2011), Indiana Law Journal: Vol. 86: Iss. 3, Article 8.

${ }^{62}$ Daniel J. Solove, and Danielle K. Citron, 'Risk and Anxiety: A Theory of Data Breach Harms' (2017), op.cit.

${ }^{63}$ See, e.g., in the US jurisprudence, Padilla v. Kentucky, 130 S. Ct. 1473, 1483 (2010) (requiring component counsel to inform client of potential "adverse immigration consequences"); Ricci v. DeStefano, 129 S. Ct. 2658 , 2672 (2009) (defining "disparate impact" as having a "disproportionately adverse effect on minorities"); Safeco Ins. Co. of America v. Burr, 551 U.S. 47, 62 (2007) (discussing "adverse effects" under the Fair Credit Reporting Act). See a general discussion about it in Ryan M. Calo, 'The Boundaries of Privacy Harm' (2011), op.cit., 1151.

${ }^{64}$ Reverse liability is a concept taken from Guido Calabresi and A. Douglas Melamed, 'Property Rules, Liability Rules, and Inalienability: One View of the Cathedral' (1972). Faculty Scholarship Series. Paper 1983, 1116 as rephrased (in the field of personal data) by Gintare Surblyte, 'Data as Digital Resource' (2016), Max Planck Institute for Innovation \& Competition Research Paper, No. 16-12, 37.

${ }^{65}$ Bilyana Petkova and Philipp Hacker, 'Reining in the Big Promise of Big Data: Transparency, Inequality, and New Regulatory Frontiers', (2016), op.cit.
} 
However, active choice models have several compatibility problems with the EU legal framework for personal data protection, particularly with regard to the General Data Protection Regulation (GDPR). Article 7(4) of the GDPR, when referring to the assessment of freedom of consent for the processing of personal data, states that "utmost account shall be taken of whether, inter alia, the performance of a contract, including the provision of a service, is conditional on consent to the processing of personal data that is not necessary for the performance of that contract". In other words, if a data subject is asked to consent to the processing of personal data (which is not necessary for the performance of that contract) in order to have access to a service or for the performance of a contract, it is highly probable that his consent is not "free", and so it is not valid under the GDPR. ${ }^{66}$

In the active choice model, individuals might "pay by data", i.e., they would be required to consent to authorize access to and processing of personal data that is not necessary for the provision of that service. Once they pay with their data, they cannot withdraw their consent freely: given that personal data would be a "counter-performance other than money", blocking that data processing would mean blocking the provision of that service. But, as also recital 42 of GDPR states, the withdrawal of consent must be "without detriment" to the data subject. In sum, it seems that the active choice model is not compatible with the EU data protection legislation. That brings us back to our proposal to introduce a right to know the value of your personal data rather than the right to have an active choice between paying with money or with personal data.

Research has shown that informing consumers about prices is a very effective way to increase attention of consumers while reading pre-contractual information papers and so to increase consumers' awareness. ${ }^{67}$ In the GDPR there are several provisions about the duty to inform data subjects. In particular, articles 13, 14 and 15 provide a list of pieces of information that should be given to data subjects in different situations. The data subject has the right to know (inter alia) the identity and the contact details of the controller, the purposes of the processing for which the personal data are intended, the categories of personal data concerned, the period for which the personal data will be stored, from which source the personal data originate, and if applicable, whether it came from publicly accessible sources, the existence of data subject's rights, the existence of automated decision-making, including profiling and, at least in those cases, meaningful information about the logic involved, as well as the significance and the envisaged consequences of such processing for the data subject. ${ }^{68}$

Although this is an extensive list of information duties, there is no specific provision referring to the economic value of personal data or personal profiling. Data controllers should inform individuals about the purpose of data processing. If data controllers process personal data as a counter-performance other than money, they should clearly declare that purpose to the data subject, otherwise any processing of personal data which are not necessary for the declared purpose (e.g., performance of a contract) would be a breach of the data minimization principle and the purpose limitation principle. ${ }^{69}$ In other words, any case in which unnecessary ${ }^{70}$ personal data is

\footnotetext{
${ }^{66}$ See the definition of "consent" at Article 4, GDPR.

${ }^{67}$ Richard G. Newell, Juha V. \& Siikamäki, 'Nudging Energy Efficiency Behaviour: The Role of Information Labels', (2014), op.cit.

${ }^{68}$ See article 13(1-2), 14(1-2), 15(1), GDPR.

${ }^{69}$ Article 5(1): "(personal data shall be: "adequate, relevant and limited to what is necessary in relation to the purposes for which they are processed" (lett. b) and "collected for specified, explicit and legitimate purposes and not further processed in a manner that is incompatible with those purposes" (lett. c).

70 i.e., not necessary for the performance of the contract at stake between data controller and data subject.
} 
collected as a "counter-performance other than money" for the provision of a service, it must be declared.

Obviously, unnecessary personal data (for instance, via cookies) are often collected via "alternative" purposes, such as improving the provision of a digital service or improving the experience of customers. Although data controllers should declare that personal data which are not necessary for the performance of a contract are collected as an alternative payment for that service, they do not have any duty to "price" those data or to inform users about these prices. That is why we propose de lege ferenda adding a new right to information to article 13 and 14 GDPR: in each data processing where the value of customers' personal data is relevant for the economic transaction, the price of these data should be communicated to the consumer.

To further concretize this provision, Data Protection Authorities should be entitled to monitor and enforce this obligation. They could ex ante release guidelines about actual prices to be set for personal data, releasing tables for personalization of prices, describing circumstances in which these calculations could vary and ex post monitor and investigate if data controllers respect these guidelines.

\section{Problems of pricing privacy and possible solutions}

In this section we discuss some problems of the idea to introduce the right to know the value of our own personal data in EU data protection law. In Section 5.1 we discuss practical problems and in Section 5.2 we discuss broader moral problems.

\subsection{Practical problems}

There are several practical problems raised by the implementation of the right to know the value of your personal data. The first problem is that of determining the actual prices. As discussed in Section 3, there are several methods for this. A choice can be made for one of these methods, but each choice may have drawbacks in the ways the calculation reflects the actual value of personal data. In other words, each method for determining prices is simply a reflection, an approximation of the actual value and may sometimes be a close estimate, but at other times significantly wrong. We think this may still work, as choosing a method, even when it occasionally is off mark, is better than nothing.

A second, related practical problem is who should do the pricing. The most obvious choice is to let data controllers do the pricing, as they may have the best knowledge to do this and it lays the burden of this task on the plate of those who profit from the data. Still, it is obvious that data controllers will be reluctant, to say the least, to pick up this task. First, it means yet another obligation to them, in which they have to be compliant and which will involve additional costs, perhaps yielding reduced profits. Second, data controllers may fear that their business models will be revealed. When consumers know the value of their personal data, they may also be able to see how much data controllers profit from these data. Although we think this actually constitutes a good reason to provide data subjects with this information, data controllers may argue that this reduces their competitiveness. When the value of personal data for each data controller, specifically data brokers, is transparent, it also reveals how (and how much) money these organisations are making. This reveals their business models and, when copied by competitors, may render them out of 
business. However, there may also be opportunities for businesses here. Research shows that consumers that experience more control (i.e., who are able to manage and protect their privacy, for instance via privacy settings) are up to $52 \%$ more willing to share information than those who are not. $^{71}$

When deciding that data controllers should do the pricing, it should also be taken into account that they may have something to gain from modifying the prices. When online services are paid with by personal data, it is profitable for data controllers to argue that the personal data has little value. In that way, they will get more personal data for their services. When payments are made with money, prices can be negotiated. When payments are made with personal data, this is no different. However, when the counterparty can first determine how much you money (i.e., your personal data) is worth before negotiating the price, this may be unfair. We think this problem can be addressed by creating objective rules for the pricing system in combination with mandatory transparency and supervision of data protection authorities, but this is something to take care of.

This brings us to the third problem, which is that supervision and enforcement may be complicated. It may be argued that it will be quite different a task than they are used to for Data Protection Authorities to supervise these monetary issues. In response to this, we would argue that Data Protection Authorities would have to focus on legal compliance with this provision to provide information on the value of personal data, which is not very different from other compliance issues in the data protection domain. Supervision would start with verifying whether such information is actually provided. If so, the next step would be to verify whether the information was provided correctly and in an appropriate way. This problem would be similar to checking compliance with other information duties that data controllers have under articles 13 and 14 of the GDPR. Checking whether pricing information was provided correctly is something that can be checked by comparing prices with similar organisations and that can be realised with the investigative and corrective powers that Data Protection Authorities have under articles 31 and 58 of the GDPR. Data Protection Authorities can (ex ante) release appropriate guidelines with specific templates for the calculation of prices (e.g. some schemes, examples and specific proposals) and (ex post) check how data controllers implement such guidelines.

A fourth problem are so-called "privacy externalities"72. An example of this is that some data may be already made public by data subjects through social networks. Paying with personal data that is available for free elsewhere may be a hard business case. However, it should be kept in mind that when data subjects disclose their personal data online, this does not imply consent to use or reuse these data for any given purpose. Further processing or reuse of data is subject to new or additional consent of the data subject. Another example is that, with the development of data retrieval technologies (i.e., data mining, machine learning, profiling) $)^{73}$ more and more data can be

\footnotetext{
${ }^{71}$ John Rose, Olaf Rehse, and Björn Röber, The value of our digital identity (2016, New York: The Boston Consulting Group), p. 13.

${ }^{72}$ Nicola Jentzsch, The State-of-the-art of Cyber-Security and Privacy, op.cit., § 3.2.2.2. See also Stefania Gnesi, Ilaria Matteucci, Corrado Moiso, Paolo Mori, Marinella Petrocchi and Michele Vescovi, 'My Data, Your Data, Our Data: Managing Privacy Preferences in Multiple Subjects Personal Data', in B. Preneel and D. Ikonomou (eds.), Privacy Technologies and Policy, Lecture Notes in Computer Science, (2014) Vol. 8450, pp. 154-171.

${ }^{73}$ Toon Calders and Bart H.M. Custers, 'What is data mining and how does it work?', in Bart H.M. Custers, Toon Calders, Bart Schermer, Tal Zarsky (eds.) Discrimination and Privacy in the Information Society (2013, Springer, nr. 3. Heidelberg).
} 
inferred or predicted from fewer and fewer raw personal data. ${ }^{74}$ This also changes the value of personal data. A final example is that personal data disclosed by a data subject may reveal data referring to other individuals ${ }^{75}$ (e.g., DNA, marital status). Accordingly, it has been argued that personal data of individuals are increasingly shifting towards multiple subjects' personal data, where information is interdependently related to multiple transaction parties. ${ }^{76}$ Consequently, it is very difficult for individuals to control this chaotic flow of personal data and difficult for data controllers to set a stable price for them. Although all these examples influence the value of personal data, they do not affect the question whether there should be a right to know the value of your personal data.

A final problem is that it may not be clear how and when the pricing information should be provided. Should it be in the privacy policy or in the general terms and conditions, should it be presented when registering for an online service or should it be send to users in period news messages? We would argue that the best approach in terms of transparency would be to use all these sources. However, it does not have to be decided in legislation, we think. The provision of this information can simply follow the reasoning of all the other information duties for data controllers laid down in articles 13 and 14 of the GDPR. These information duties are not phrased in a way that determines where and when such information should be provided. ${ }^{77}$ The only requirement is how the information should be provided, which can be found in Article 7, paragraph 2, which states that all such information should be presented in a manner which is clearly distinguishable from the other matters, in an intelligible and easily accessible form, using clear and plain language. This provision can also be applied to information on the value of someone's personal data.

\subsection{Moral problems}

Apart from the practical problems mentioned above, there are also some ethical and moral problems that can be identified when going down this road of pricing privacy. ${ }^{78}$ The first problem is that personal data rapidly becomes a commodity that can be traded. Personal data, however, are closely related to the privacy of a data subject. Commodification of privacy may be considered an undesirable approach, as privacy and other human rights are inalienable and non-negotiable. In the US, trading personal data without any legal restrictions is very common, but this is an approach that is frowned upon in the EU. The EU created the GDPR (and preceding legislation) exactly to avoid uncontrolled spreading and use of personal data in order to enable data subjects to protect their personal data. EU legislation specifically empowers data subjects with control rights. Therefore, we argue that commodification of privacy and personal data is not at risk in our proposal to introduce a right to know the value of your personal data. Even when people want to sell away their data

\footnotetext{
${ }^{74}$ Michal Kosinskia, David Stillwella, \& Thore Graepelb, 'Private traits and attributes are predictable from digital records of human behavior', in Proceedings of the National Academy of Sciences of the United States of America (2013), 110(15): 5802-5805.

${ }^{75}$ Nicola Jentzsch, The State-of-the-Art, op.cit., § 3.2.2.2.

${ }^{76}$ Stefania Gnesi, Ilaria Matteucci, Corrado Moiso, Paolo Mori, Marinella Petrocchi and Michele Vescovi, 'My Data, Your Data, Our Data: Managing Privacy Preferences in Multiple Subjects Personal Data, 2014, op.cit., pp. $154-171$.

${ }^{77}$ See, e.g., Sandra Wachter, Brent Mittelstadt, and Luciano Floridi, 'Why a Right to Explanation of Automated Decision-Making Does Not Exist in the General Data Protection Regulation' (2016), International Data Privacy Law, Forthcoming.

${ }^{78}$ For a general view about moral problems related to "monetization" of personal data see e.g. Nicola Jentzsch, State-ofthe-Art of the Economics of Cyber-Security and Privacy, IPACSO - Innovation Framework for ICT Security Deliverable, (2016) No. 4.1, § 3.7.
} 
privacy, they are unable to do this, from a legal perspective. They will always have several inalienable rights with regard to their personal data, regardless of whom is processing them. Also, they will always have the right to withdraw their consent to such processing. ${ }^{79}$ Hence, personal data can be commodified, but personal data rights will still be intact.

A second problem of pricing privacy is that the value of personal data of some people will be worth more than that of others. As was already explained in Section 3, personal data of people who have more to spend (and consequentially higher propensity to consume) will probably be worth more to data controllers. As a result, there may occur something which can be called ex ante discrimination, which personal data of poor people is less valuable and personal data of rich people is more valuable. This may reinforce existing disparities in society. ${ }^{80}$ Poorer people are generally more price-sensitive, ${ }^{81}$ while richer people are less price-sensitive, but have a higher propensity to consume. When attracting customers, companies may offer larger discounts to interesting (i.e., profitable, rich) customers. As such, rich people may get better prices and poor people may get lousy offers. ${ }^{82}$ Actually, this is disputable: there are several more factors influencing price discrimination, e.g. it has been argued that personalization of online commercial offers should work to the benefit of more price-sensitive people, and so there should be lower costs for consumers with fewer resources. $^{83}$

In sum, although data price discrimination might be a serious problem, potentially increasing stigmatization and polarisation in society, there are several more factors and variables that distort its effects, so that pricing digital identities cannot prove to be a discriminatory practice itself. To the contrary, it would be a dynamic tool enhancing awareness and controllership also against unfair practices of data controllers. Similarly, we do not think this problem can be solved in data protection legislation alone. It may require stronger legislations in the domains of nondiscrimination law, competition law and criminal law.

\section{Conclusions}

In this paper we analyzed whether consumers/users should have a right to know the value of their personal data. The main reason to consider this question is because, on the one hand, the commodification of digital identities is an emerging reality in the data-driven economy and, on the other hand, individuals do not seem to be fully aware of the monetary value of their personal data

\footnotetext{
${ }^{79}$ Bart H.M. Custers, Simone van der Hof, Bart W. Schermer, Sandra Appleby-Arnold and Noellie Brockdorff, 'Informed Consent in Social Media Use. The Gap between User Expectations and EU Personal Data Protection Law' (2013), in Script-ed: a journal of law and technology 10(4): 435-457.

${ }^{80}$ Bart H.M. Custers, 'Data Dilemmas in the Information Society', in Bart H.M. Custers, Toon Calders, Bart W. Schermer, Tal Zarsky (ed.) Discrimination and Privacy in the Information Society (2013, nr. 3. Heidelberg: Springer)

${ }^{81}$ See, e.g., Andrew Odlyzko, 'Privacy, economics, and price discrimination on the Internet' (2003) Proceedings of the 5th international conference on Electronic commerce (ACM) 355. See also Exec. Office of The President of United States, Big Data And Differential Pricing, http://www.whitehouse.gov/sites/default/files/whitehouse_files/docs/Big_Data_Report_Nonembargo_v2.pdf (accessed 12 June 2017), p. 17.

${ }^{82}$ See also Cathy O'Neil, Weapons of Math Destruction; How big data increases inequality and threatens democracy, (2016, New York: Crown).

${ }^{83}$ See Exec. Office of The President of United States, Big Data And Differential Pricing, (2015) 17, http://www.whitehouse.gov/sites/default/files/whitehouse files/docs/Big_Data_Report_Nonembargo_v2.pdf (accessed 12 June 2017): "[I]f historically disadvantaged groups are more price-sensitive than the average consumer, profitmaximizing differential pricing should work to their benefit" in competitive markets".
} 
and tend to underestimate their economic power within the data-driven economy and to passively succumb to the propertization of their digital identity. Introducing a right for data subjects to know the value of their personal data may increase their awareness and controllership on their own personal information and enable them to acquire higher awareness about their power in the digital market and effectively empower them for the protection of their information privacy.

We have shown that the current data-driven economy de facto already monetizes personal data. A variety of different online business models exist in practice, with different incentives for data subjects to 'pay' with their data. Also, EU legislation is increasingly taking into account this new reality. Next, we investigated different methods for quantifying the value of personal data, not to determine the actual prices of personal data, but to show that the monetary value of personal data can be quantified, a conditio-sine-qua-non for the right to know the value of your personal data. Furthermore, active choice models, in which users are offered the option to pay for online services, either with their personal data or with money, were examined. However, it was concluded that these models are incompatible with EU data protection law. Hence, these models do not provide a viable alternative to increase awareness and control of data subjects regarding their personal data.

Therefore, a right for data subjects to know the value of their personal data is the most practical and realistic approach to empower data subjects towards this commodification of digital identities. Informing consumers about prices is a very effective way to increase attention of consumers while reading pre-contractual information papers and so to increase consumers' awareness. To some extent, there already is an obligation for data controllers under EU data protection law to inform data subjects when they consider providing personal data as 'payment'. I.e., when personal data is collected that is strictly speaking unnecessary for performing the contract, the personal data is collected as a "counter-performance other than money" and must therefore be declared. If not, any such processing of personal data would be a breach of the data minimization principle and the purpose limitation principle.

In articles 13, 14 and 15 the GDPR there are already several provisions about the duty to inform data subjects. It would be quite straightforward to add a new right to information to article 13 and 14 GDPR reading something like: in each data processing where the value of customers' personal data is relevant for the economic transaction, the price of these data should be communicated to the consumer. Data Protection Authorities should be entitled to monitor and enforce such an obligation. They could ex ante release guidelines about actual prices to be set for personal data, releasing tables for personalization of prices, describing circumstances in which these calculations could vary and ex post monitor and investigate if data controllers respect these guidelines.

It is obvious that this proposed right to know the value of your personal data also entails several practical problems (such as choosing a pricing method, issues regarding control and consent and issues regarding governance and enforcement) and moral problems (such as the commodification of inalienable and non-negotiable human rights and the potential reinforcement of existing disparities in society). We recognize that some of these problems are significant and provided some suggestions to mitigate them. Even though not all of these problems can be solved, we think these do not outweigh the benefits of introducing a right to know the value of your personal data. 


\section{References}

Corien Prins, The Propertization of Personal Data and Identities (2004), EJCL, www.ejcl.org/83/art83-1.html (accessed 12 June 2017). Nadhezda Purtova, The Illusion of Personal Data as No One's Property (2015), Law, Innovation and Technology, vol. 7, n. 1, 2015.

Wolfie Christl and Sarah Spiekermann, Networks of Control: A Report on Corporate Surveillance, Digital Tracking, Big Data \& Privacy (Facultas Verlags - und Buchhandels AG, 2016).

Brenda Reddix-Smalls, 'Credit Scoring and Trade Secrecy: An Algorithmic Quagmire or How the Lack of Transparency in Complex Financial Models Scuttled the Finance Market', (2011) 12 U.C. Davis Bus. L.J. 87, $117-18$.

Frederik Z. Borgesius., Behavioural Sciences And The Regulation Of Privacy On The Internet (2014), Amsterdam Law School Legal Studies Research Paper No. 2014-54.

World Economic Forum, Rethinking Personal Data: Strengthening Trust (2012), http://www3.weforum.org/docs/WEF_IT_RethinkingPersonalData_Report_2012.pdf (Accessed 9 June 2017 ), p. 9.

Bart H.M. Custers, 'Click here to consent forever; Expiry dates for informed consent', (2016), Big Data \& Society, $1-6$.

Arslan Aziz and Rahul Telang, 'What Is a Digital Cookie Worth?' (March 31, 2016). Available at SSRN: https://ssrn.com/abstract=2757325 (accessed 12 June 2017).

Cristiano Codagnone, Francesco Bogliacino and Giuseppe Veltri, Testing CO2/Car labelling options and consumer information, Final Report (2013), available at http://ec.europa.eu/clima/policies/transport/vehicles/labelling/studies en.htm.

Gianclaudio Malgieri, 'Ownership” of Customer (Big) Data in the European Union: Quasi-Property as Comparative Solution?', (2016) Journal of Internet Law, Vol. 20, n.5.

Arslan Aziz and Rahul Telang, 'What Is a Digital Cookie Worth?' (2016). Available at SSRN: https://ssrn.com/abstract=2757325 (accessed 12 June 2017).

Richard G. Newell, Juha V. \& Siikamäki, 'Nudging Energy Efficiency Behaviour: The Role of Information Labels', (2014) 1 J. Association Environmental \& Resource Economists 555, 593, Cristiano Codagnone, Francesco Bogliacino and Giuseppe Veltri, Testing CO2/Car labelling options and consumer information, Final Report (2013), available at http://ec.europa.eu/clima/policies/transport/vehicles/labelling/studies en.htm (accessed 12 June 2017), at 9.

John Rose, Olaf Rehse, and Björn Röber, The value of our digital identity (2016, New York: The Boston Consulting Group). See also Arslan Aziz and Rahul Telang, 'What Is a Digital Cookie Worth?', op.cit.

Guido Calabresi and A. Douglas Melamed, 'Property Rules, Liability Rules, and Inalienability: One View of the Cathedral' (1972), Faculty Scholarship Series, Paper 1983, 1116

Gintare Surblyte, 'Data as Digital Resource', (2016). Max Planck Institute for Innovation \& Competition Research Paper No. 16-12.

Daniel J. Solove, and Danielle K. Citron, 'Risk and Anxiety: A Theory of Data Breach Harms' (forthcoming 2017) 96 Texas Law Review.

Bilyana Petkova and Philipp Hacker, 'Reining in the Big Promise of Big Data: Transparency, Inequality, and New Regulatory Frontiers' (2016), Lecturer and Other Affiliate Scholarship Series. Paper 13.

Emily Steel, Callum Locke, Emily Cadman and Ben Freese, 'How much is your personal data worth?', Financial Times, (12 June 2013), available at http://www.ft.com/cms/s/2/927ca86e-d29b-11e2-88ed00144feab7de.html?ft site=falcon\#axzz2z2agBB6R (accessed 12 June 2017).

Emily Steele, Financial worth of data comes in at under a penny a piece, Financial Times, June 12, 2013.

Lauren Henry Scholz, 'Algorithmic Contracts' (2016), Stanford Technology Law Review, Forthcoming. Available at SSRN: https://ssrn.com/abstract=2747701 (accessed 12 June 2017)

Ningning Chen, Xinlei Oscar Wang, Prasant Mohapatra, Aruna Seneviratne, 'Characterizing privacy leakage of public WiFi networks for users on travel Conference Paper' in Proceedings IEEE INFOCOM (2013).

John Hancock (2015): 'John Hancock Introduces a Whole New Approach to Life Insurance in the U.S. that Rewards Customers for Healthy Living' (April 8, 2015), http:/www.johnhancock.com/about/news details.php?fn=apr0815text\&yr=2015, (accessed 12 June 2017).

Nicola Jentzsch, State-of-the-Art of the Economics of Cyber-Security and Privacy, IPACSO - Innovation Framework for ICT Security Deliverable, No. 4.1 (2016).

Nicola Jentzsch, Andreas Harasser, Sören Preibusch, Monetising Privacy - An Economic Model of the Pricing of Personal Information, ENISA Report, (2012) Greece, www.enisa.europa.eu/activities/identity (accessed 12 June 2017).

Natasha Lomas, 'Handshake Is A Personal Data Marketplace Where Users Get Paid To Sell Their Own Data', Tech Crunch, (2 September 2013), <https://techcrunch.com/2013/09/02/handshake/> (accessed 28 May 2017).

Jay MacDonald, 'How much are your personal details worth?', (21 February 2006), Bankrate.com, http://www.bankrate.com/nsccan/news/pf/20060221b1.asp (accessed 12 June 2017).

More-with-mobile, 'Prices and Value of Consumer Data' (2013) http://www.more-with-mobile.com/2013/06/pricesand-value-of-consumer-data.html (accessed 12 June 2017).

OECD, Data-driven Innovation for Growth and Well-being, Interim Synthesis Report (2014). 
Bart H.M. Custers \& Helena Ursic, 'Big data and data reuse: a taxonomy of data reuse for balancing big data benefits and personal data protection' (2016), International Data Privacy Law 6(1): 4-15.

Bart H.M. Custers, 'Predicting Data that People Refuse to Disclose; How Data Mining Predictions Challenge Informational Self-Determination', (2012) Privacy Observatory Magazine 2012(3).

Paul Boutin, 'The Secretive World of Selling Data about You' (2016), Newsweek, http://www.newsweek.com/secretive-world-selling-data-about-you-464789 (accessed 12 June 2017).

OECD, Exploring the Economics of Personal Data: A Survey of Methodologies for Measuring Monetary Value, OECD Digital Economy Papers, No. 220, (2013, OECD Publishing).

Alessandro Acquisti, Leslie John and George Loewenstein, 'What Is Privacy Worth?', (2013) Journal of Legal Studies: 42 (2)1, http://chicagounbound.uchicago.edu/jls/vol42/iss2/ (accessed 28 May 2017).

Bilyana Petkova and Philipp Hacker, 'Reining in the Big Promise of Big Data: Transparency, Inequality, and New Regulatory Frontiers', (2016) Yale Law School: Lecturer and Other Affiliate Scholarship Series, paper 13.

Bart H.M. Custers, Simone van der Hof S\& Bart Schermer, 'Privacy Expectations of Social Media Users: The Role of Informed Consent in Privacy Policies', (2014) Policy and Internet 6(3): 268-295.

See Daniel J. Solove \& Danielle Keats Citron, 'Risk and Anxiety: A Theory of Data Breach Harms', (2017) GW Law School Public Law and Legal Theory Paper No. 2017-2.

Ryan M. Calo, 'The Boundaries of Privacy Harm' (2011), Indiana Law Journal: Vol. 86: Iss. 3, Article 8. Group), p. 13.

Stefania Gnesi, Ilaria Matteucci, Corrado Moiso, Paolo Mori, Marinella Petrocchi and Michele Vescovi, 'My Data, Your Data, Our Data: Managing Privacy Preferences in Multiple Subjects Personal Data', in B. Preneel and D. Ikonomou (eds.), Privacy Technologies and Policy, Lecture Notes in Computer Science, (2014) Vol. 8450, pp. 154-171.

Toon Calders and Bart H.M. Custers, 'What is data mining and how does it work?', in Bart H.M. Custers, Toon Calders, Bart Schermer, Tal Zarsky (eds.) Discrimination and Privacy in the Information Society (2013, Springer, nr. 3. Heidelberg).

Michal Kosinskia, David Stillwella, \& Thore Graepelb, 'Private traits and attributes are predictable from digital records of human behavior', in Proceedings of the National Academy of Sciences of the United States of America (2013), 110(15): 5802-5805.

Sandra Wachter, Brent Mittelstadt, and Luciano Floridi, 'Why a Right to Explanation of Automated DecisionMaking Does Not Exist in the General Data Protection Regulation' (2016), International Data Privacy Law, Forthcoming.

Bart H.M. Custers, Simone van der Hof, Bart W. Schermer, Sandra Appleby-Arnold and Noellie Brockdorff, 'Informed Consent in Social Media Use. The Gap between User Expectations and EU Personal Data Protection Law' (2013), in Script-ed: a journal of law and technology 10(4): 435-457.

Bart H.M. Custers, 'Data Dilemmas in the Information Society', in Bart H.M. Custers, Toon Calders, Bart W. Schermer, Tal Zarsky (ed.) Discrimination and Privacy in the Information Society (2013, nr. 3. Heidelberg: Springer)

Andrew Odlyzko, 'Privacy, economics, and price discrimination on the Internet' (2003) Proceedings of the 5th international conference on Electronic commerce (ACM) 355.

Exec. Office of The President of United States, Big Data And Differential Pricing, (2015) 17, http:/www.whitehouse.gov/sites/default/files/whitehouse files/docs/Big Data Report Nonembargo v2.pdf (accessed 12 June 2017), p. 17.

Cathy O'Neil, Weapons of Math Destruction; How big data increases inequality and threatens democracy, (2016, New York: Crown). 